\section{Memoriais on-line às vítimas da Covid-19 no Brasil: narrativas sensíveis à dor alheia}

Sonia Aguiar

Resumo:

À luz de literatura anglófona sobre a mediação da dor alheia (livre tradução para mediating distant suffering) na mídia e sobre testemunhos midiáticos (media witnessing), este artigo reflete sobre as narrativas adotadas por jornalistas em relação às vítimas da Covid-19, após o aumento acelerado de mortes pela doença no Brasil. Parte-se do impacto midiático causado pela criação do site Inumeráveis, construído de forma colaborativa, para analisar o tratamento adotado pelo hotsite Memorial Covid-19 do portal G1, criado um mês antes e alimentado por profissionais das emissoras afiliadas à Rede Globo de televisão. Argumenta-se que ambos os memoriais são fruto de uma "guinada moral" em relação à cobertura jornalística da pandemia, que até certo momento supervalorizou os números de doentes e mortos, sem considerar as experiências de vida por trás desses acontecimentos. Assim, conclui-se que os memoriais substituem os relatos baseados em índices racionais da pandemia pelas narrativas sensíveis ao sofrimento dos por ela afetados, pautados por testemunhos e pelo princípio de proximidade.

Palavras-chave: Cobertura da pandemia. Narrativas sensíveis. Jornalismo de proximidade.

Online memorials to victims of Covid-19 in Brazil: sensitive narratives on others' pain

\begin{abstract}
:
In the light of anglophone literature on mediating distant suffering and media witnessing, this article reflects on the narratives adopted by Brazilian journalists in relation to the victims of Covid-19, after the accelerated increase of deaths from that disease in Brazil. This article is built from the media impact caused by the creation of the website Innumerable, developed in a collaborative way, to analyze the treatment adopted by the Memorial Covid-19 of the G1 portal, created a month before it and with content produced and uploaded by journalists from the stations affiliated to Rede Globo, Brazil's largest TV broadcaster. It is argued that both memorials result from a "moral turn" in relation to the news coverage on the pandemic, that overestimated the numbers of sick and dead, without considering their life experiences behind these events. Thus, the article comes to the conclusion that memorials replace reports based on rational indices of the pandemic by narratives sensitive to the suffering of those affected by it, guided by testimonies and the principle of proximity.
\end{abstract}

Keywords: Pandemic coverage. Sensitive narratives. Proximity as newsworthiness.
Recebido em: 16.09 .20

Aprovado em: 21.02.21

\section{Sonia Aguiar}

Jornalista graduada pela UFF, com Mestrado e Doutorado em Comunicação (ECO-UFRJ) e pós-doutorado em Geografia Regional pelo PPGeo-UFF. Profa. do Curso de Jornalismo e do Mestrado em Comunicação da Universidade Federal de Sergipe (UFS).

E-mail: saguiar@academico.ufs.br
Estudos em Jornalismo e Mídia v.18, n.1, jan./jun. 2021.

ISSNe 1984-6924 
${ }^{1}$ Disponível em: https:// g1.globo.com/bemestar/ coronavirus/.

${ }^{2}$ Fonte: https:// g1.globo.com/politica/ noticia/2020/06/08/ veiculos-de-comunicacao-formam-parceria-para-dar-transparencia-a-dados-de-covid-19.ghtml.

3"Relato descritivo de memórias. Escrito em que se relatam e registram fatos memoráveis; memórias", conforme verbete do $\mathrm{Mi}$ chaelis - Dicionário Brasileiro da Língua Portuguesa.

Disponível em: https:// michaelis.uol.com.br/ palavra/9oNG0/memorial/. Acesso em: 20 ago. 2020.

${ }^{4}$ Disponível em: http:// especiais.g1.globo.com/bemestar/coronavirus/memorial-vitimas-covid-19/\#/

${ }^{5}$ Rogério Oliveira, Rogério Zé, Alana Rizzo Guilherme Bullejos,

Gabriela Veiga, Giovana Madalosso, Rayane Urani, Jonathan Querubina.

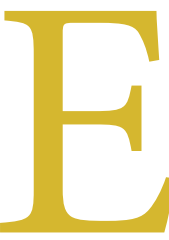

ste artigo tem origem na observação sistemática da atuação de emissoras afiliadas à Rede Globo de televisão empreendida nos últimos cinco anos, em especial na Região Nordeste, como parte das pesquisas em Geografias da Comunicação Regional e do jornalismo local-regional. Com o advento da pandemia da Covid-19, uma atenção especial passou a ser dedicada ao trabalho do portal G1 (cujos conteúdos são alimentados pelas referidas emissoras), por ter criado um painel de dados sobre a disseminação do coronavírus no país, graças a essa rede de produção jornalística de âmbito nacional (AGUIAR, 2020).

Em 8 de junho de 2020, porém, o Painel Covid-19, publicado na seção Coronavírus do website Bem Estar do Portal $\mathrm{G1}^{1}$, foi desativado e a divulgação dos dados passou a ser feita por um consórcio de veículos de imprensa criado pelos grupos Globo, Folha e $O$ Estado de S. Paulo ${ }^{2}$. A partir de então, não foi mais possível fazer consultas a situações regressas da pandemia, como o Painel propiciava. Mas outros recursos de informação e análise foram sendo incorporados pelos veículos do consórcio para dar conta da síndrome respiratória grave, tecnicamente denominada de SARS-CoV-2 ou Covid-19, que desde março de 2020 tem afetado milhões de pessoas de diferentes idades, crenças, cor, culturas, profissões, posições sociais e condições financeiras em todo o mundo

Apesar de se tratar de um vírus pouco conhecido, dados sobre a Covid-19 são atualizados diariamente por inúmeros veículos jornalísticos espalhados pelo mundo, ainda que haja subnotificações por parte dos órgãos de saúde e tentativas de ocultar informações oficiais por parte de alguns governantes. No entanto, a profusão informacional de dados sobre a doença acabou provocando um efeito colateral socialmente danoso. À medida que a contaminação se acelerava e se expandia geograficamente, tanto em quantidade de novos casos quanto de mortes, a cobertura foi se massificando e se desumanizando, ao deixar de lado as circunstâncias dramáticas das pessoas afetadas, que acabavam reduzidas a números.

A percepção pública negativa desse tratamento gerou um movimento de solidariedade pautado pelo luto coletivo, que se materializou em dois websites formatados como memoriais ${ }^{3}$ virtuais às vítimas fatais da Covid-19: o do portal nacional G14, inaugurado em março de 2020, com uma postagem do G1 RN sobre um padre potiguar que faleceu em Recife; e o projeto Inumeráveis (https:// inumeraveis.com.br/), lançado no dia 30 de abril por iniciativa do artista multimídia paulistano Edson Pavoni.

O segundo site, de caráter colaborativo, foi desenvolvido, inicialmente, por oito pessoas ${ }^{5}$. Mas logo recebeu a adesão de voluntários (incluindo jornalistas e estudantes de jornalismo), que passaram a alimentar continuamente o memorial com histórias de pessoas que perderam suas vidas após contaminação do coronavírus no Brasil: "não há quem goste de ser número/ gente merece existir em prosa", diz a epígrafe da "lápide virtual" em que estão gravados os nomes e idade das vítimas (BASÍlIO, 2020). Como escreveu Pavoni em seu Instagram: "O desconforto de acordar todos os dias com um novo número de mortos, depois de um tempo vai passando e a gente acaba ficando insensível. Já as histórias penetram no nosso coração em um lugar onde os números não conseguem chegar".

O painel Inumeráveis é composto por uma sucessão de nomes de vítimas fatais da Covid-19, em ordem alfabética, seguidos da idade e de uma frase com link que remete aos textos editados sobre a trajetória de cada um. Estes, por sua vez, são conectados a outra listagem, a das cidades onde cada pessoa homenageada nasceu (também em ordem alfabética). Já as histórias do Memorial do G1 são organizadas em ordem cronológica reversa (da mais recente às mais antigas), como nos blogs, com indicação da data da morte, a cidade e sigla do Estado, o nome completo em destaque, ao lado da foto da pessoa (ou vídeo), e por fim, um link de "saiba mais" 
que remete para reportagens dos sites regionais vinculados às emissoras afiliadas à Rede Globo.

No site Inumeráveis, os "textos-tributos", criados pelos jornalistas voluntários a partir dos questionários disponíveis on-line, são carregados de recordações de parentes e amigos, muito longe da objetividade recomendada pelos compêndios da profissão e dos manuais de redação dos veículos. No Memorial do G1 os dados biográficos são seguidos de mini-apresentação personalizada, geralmente com alguma citação de familiar, amigo ou colega de trabalho, ou de um registro dos últimos acontecimentos antes da morte, ou ainda de um texto expressivo de adeus e luto. Porém, muitas vezes a matéria vinculada a esse mural virtual é publicada pelas editorias regionais bem depois da data do falecimento indicada na apresentação, seguindo um protocolo de oficialização do acontecimento.

Os dois memoriais buscam estimular a colaboração das pessoas próximas no relato das histórias de vida das vítimas. "E é graças a esses relatos que o G1 pode dar rostos aos números, mostrar que há pessoas por trás das estatísticas”, explica matéria publicada em junho de 2020 pelo G1 Minas Gerais (2020). O texto afirma que além da homenagem aos que partiram, o Memorial é também uma forma de sensibilizar a sociedade sobre a importância de se proteger individual e coletivamente. A reportagem deixa claro que o trabalho dos profissionais de jornalismo só obtém êxito graças aos relatos dos familiares, que compartilham lembranças e assim ajudam a dar rosto aos números apresentados na cobertura da pandemia.

Já o Inumeráveis é alimentado por uma rede de jornalistas e estudantes de jornalismo voluntários, que no início de setembro de 2020 passava de 260 , conforme listagem nominal disponível no site ${ }^{6}$. A ideia dos criadores foi reforçar o poder da empatia e cooperação entre as pessoas. "É uma celebração de cada vida que existiu e que existe, e de como podemos entrelaçá-las para construir memória, afeto, respeito e futuro", exalta a apresentação do memorial. "Vivos ou mortos, nunca seremos números", ressalta.

Estatísticas são necessárias. Mas palavras também. Se nem todas as vítimas tiveram a chance de ter um velório ou de se despedir de seus entes queridos, queremos que tenham ao menos a chance de terem a sua história contada. De ganharem identidade e alma para seguir vivendo para sempre na nossa memória (INUMERÁVEIS, s.d.)

Essas duas iniciativas refletem o que Ong (2009 apud KYRIAKIDOU, 2015) identifica como "guinada moral" da mídia acerca do sofrimento alheio (distant suffering, em inglês) e das sensibilidades emocionais e políticas das audiências midiáticas sobre as vítimas de acontecimentos distantes. Manifestações com esse viés moral em relação aos dados da Covid-19, afirmando que não são apenas números, mas vidas, já apareciam em diferentes veículos brasileiros. Mas essa cobrança ética também inspirou outros projetos de solidariedade com força midiática. No Dia das Mães (10 de maio de 2020), por exemplo, o coletivo Projetemos garimpou no Inumeráveis algumas homenagens a mães e filhas e as projetou em prédios de Belo Horizonte. Onze dias depois, a revista Carta Capital publicou matéria com reproduções de trechos de algumas dessas narrativas, nas quais fica claro o tom de afeto em relação aos personagens e suas histórias de vida: "tia-mãe, a dona do abraço mais quentinho"; "apaixonado pai de duas meninas"; "amava ajudar a salvar vidas"; "Quando sua esposa estava triste ele dançava bolero para animá-la" (BASÍLIO, 2020, on-line).

Essa guinada editorial pôde ser observada, particularmente, nos veículos do Grupo Globo, a partir do dia em que o Brasil ultrapassou a casa dos 10 mil mortos pelo novo coronavírus. No domingo 30 de maio de 2020, a primeira página do jornal $O$ Globo foi inteiramente editada como um mural de nomes, tendo como manchete "10 MIL HISTÓRIAS" (assim, em caixa alta, ocupando a largura da página)",

${ }^{6}$ Disponível em: https:// inumeraveis.com.br/sobre/.

${ }^{7}$ Ver em: https://revistaforum.com.br/midia/ em-capa-historica-jornal-o-globo-faz-memorial-gigante-aos-mais-de-10-mil-mortos-por-covid-19-no-brasil/. 
com base nos relatos reunidos no site Inumeráveis. Daí em diante, os telejornais da Globo passaram a reiterar diariamente que por trás dos números da Covid-19 havia pessoas. Não foram poucas as vezes em que o Jornal Nacional (JN) encerrou a edição em silêncio, em homenagem aos mortos da pandemia. Já a revista eletrônica dominical Fantástico optou por dramatizar os testemunhos na interpretação de artistas da emissora.

Esse redirecionamento editorial, de humanização das estatísticas, foi estendido também ao G1, o portal da Rede Globo na internet, cujos conteúdos são alimentados pelas equipes das 118 emissoras afiliadas e cinco canais próprios presentes em todas as Unidades da Federação (UFs). Por atuarem localmente, regidos pelo princípio de proximidade, os jornalistas dessas emissoras têm a possibilidade de resgatar as singularidades das histórias das vítimas brasileiras da Covid-19, de modo a apresentar um mosaico dos efeitos da pandemia no território nacional. Assim, os inumeráveis espontaneamente homenageados por parentes e amigos transformam-se nas pautas que alimentam o Memorial do G1, subtitulado "As vítimas da Covid-19: os brasileiros que perderam a vida na pandemia do coronavírus".

Como dizem Rondelli e Herschmann (2000, p. 203):

As narrativas biográficas e autobiográficas oferecem um enquadramento retrospectivo e prospectivo ao ordenarem a vida articulando memória e aspirações ("projetos") dos indivíduos, suas motivações e os significados de suas ações numa conjuntura própria de vida, conferindo uma sequência às etapas de uma trajetória pessoal.

\section{A mediação do sofrimento alheio}

Vários estudos têm sido publicados na última década, sobretudo em inglês, sobre a forma como a mídia opera a "mediação do sofrimento alheio" e como constrói narrativas testemunhais dessas dores (CHOULIARAKI, 2008; ONG, 2014; FROSH; PINCHEVSKI, 2014; KYRIAKIDOU, 2015). Em geral, os estudos são relacionados a acontecimentos que envolvem pessoas vitimadas coletivamente no próprio país ou em territórios estrangeiros. Embora nenhum deles tenha ainda alcançado todo o sofrimento causado pela pandemia de Covid-19 no mundo, a aplicação dessas reflexões aos memoriais dedicados aos mortos da doença no Brasil é convidativa.

Lilie Chouliaraki (2008, p. 3) define essa mediação como

[...] um processo por meio do qual recursos discursivos articulados tecnologicamente, como linguagem e imagem, produzem sentido sobre o sofrimento e, ao fazer isso, propõem às audiências midiáticas modos específicos de engajamento com as pessoas que sofrem à distância.

Para esta pesquisadora, essa proposição "engloba uma ampla gama de posturas éticas, que vão da responsabilidade e cuidado à indiferença e apatia, e assim, destacam o papel crucial da mídia na produção de várias formas de conectividade entre espectadores e sofredores ao longo das fronteiras nacionais" (idem).

Por meio da escolha sistemática de certas palavras e imagens, "a mídia não só expõe as audiências a espetáculos de sofrimentos alheios como, ao fazê-lo, simultaneamente as expõe a disposições específicas para sentir, pensar e agir em relação a cada instância de sofrimento" (CHOULIARAKI, 2008, p. 3, grifo da autora). Para Chouliaraki (2008), a mídia hierarquiza essas provocações aos modos de sentir, pensar e agir conforme a proximidade (física ou simbólica) entre as audiências e os sofredores, o que também determina as opções de ação sobre o infortúnio que

${ }^{8}$ Disponível em: http:// especiais.g1.globo.com/bemestar/coronavirus/memorial-vitimas-covid-19/\#/. as notícias apresentam ao seu público. Com base nessas referências, ela questiona a responsabilidade social da mídia - especialmente a televisão - e sua capacidade de levar as pessoas a sair de um voyeurismo passivo em relação à dor humana para uma ação solidária e humanitária efetiva. 
Maria Kyriakidou (2015) observa que o engajamento do público em relação ao sofrimento alheio tem sido abordado, academicamente, em três vertentes principais: em termos de compaixão, de atitude humanitária ou de indiferença. Embora a autora ressalte que a força testemunhal do sofrimento alheio é maior na comunicação audiovisual, por conta da abundância de detalhes que as imagens oferecem (eventualmente acrescidas da atmosfera de dor e pânico criada pelo som ambiente), o site Inumeráveis demonstra que palavras escritas também são capazes de provocar engajamento solidário da audiência por meio das mediações textuais. "Essa relação entre o público e os textos midiáticos não é exclusiva do caso de testemunhar sofrimento e sim uma característica mais ampla da intertextualidade da mediação" (KYRIAKIDOU, 2015, p. 219), destaca a pesquisadora.

Mas o foco dominante desses estudos de mediação do sofrimento alheio não são as mortes "avulsas" e territorialmente esparsas que povoam o noticiário cotidiano (vítimas de latrocínio, violência doméstica, acidentes de trânsito etc.) e sim o sofrimento coletivo resultante de acontecimentos que afetam várias pessoas ao mesmo tempo, em um só lugar, como acidentes de avião, desastres urbanos, catástrofes climáticas. É o caso também das crises humanitárias, como as ondas de migrantes do século 21, e sanitárias, como a provocada em todo o mundo pela pandemia do novo coronavírus.

Reportagens de desastres, crises e sofrimento humano tornaram-se uma característica comum da mídia moderna. Cenas de tragédia e catástrofes fazem parte da experiência cotidiana das audiências, que são convidadas a participar virtualmente do sofrimento dos outros à distância (KYRIAKIDOU, 2015, p. 215).

A cena de centenas de caixões sendo sobrepostos em valas comuns de cemitérios de Manaus, no primeiro auge da contaminação por coronavírus no Amazonas (em abril de 2020), é emblemática ao ponto de gerar tanto comoção quanto rejeição à sua veracidade. Frosh (2006 apud KYRIAKIDOU, 2015, p. 218) ressalta que o hiato de veracidade (veracity gap) é ainda mais proeminente na TV, apesar do aparente testemunho das imagens. A justificativa seria o fato de que "a distância acentua a desconfiança e a dúvida na mediação da experiência entre pessoas que não têm proximidade física ou conhecimento de primeira mão dela" (idem).

Para Kyriakidou (2015, p. 216), as narrativas testemunhais midiáticas - como as dos memoriais às vítimas da Covid-19 - têm duas características principais: a natureza afetiva devido à sua relação com a vulnerabilidade humana e situações traumáticas ou dolorosas; e a dotação cultural aliada ao senso de responsabilidade para interferir e agir sobre o sofrimento testemunhado.

Assim, o testemunho da mídia pressupõe a tripla distinção ressaltada por Frosh e Pinchevski (2009 apud KYRIAKIDOU, 2015, p. 217): a do testemunho "na" mídia, "através" da mídia ou "da" mídia. Testemunhos "na” mídia parecem se referir a vítimas distantes, cujo sofrimento é possível imaginar, mas cujas diferenças e estranhezas desse "outro distante" são exacerbadas na narrativa, tornando difícil a construção de empatia (como aconteceu com os chineses no início da pandemia, retratados como "culpados" pela expansão do vírus). No testemunho "através" da mídia (como o dos profissionais de saúde no quadro "Aqui Dentro", do $\mathrm{JN}^{9}$ ) o público se vê diante de um conhecimento assustador da dor alheia, de modo a levá-lo a pensar que precisa fazer alguma coisa a respeito, seja por um sentimento de obrigação moral, seja por identidade cultural ou social. Por outro lado...

[...] a distância geográfica que separa o observador dos desafortunados mina o impulso moral de agir sobre os sofredores. A combinação do senso de envolvimento nos eventos que o conhecimento deles fornece com a sensação de impotência que a distância perpetua encontra-se no centro do testemunho da mídia (KYRIAKIDOU, 2015, p. 217).

${ }^{9}$ Ver em: https://g1.globo. com/jornal-nacional/ playlist/aqui-dentro-profissionais-da-saude-contam-o-que-estao-vendo-fazendo-e-sentindo.ghtml. 
O testemunho dos jornalistas (especialmente os que atuam na televisão) é geralmente entendido a partir da experiência revelada e narrada de ter estado "lá" e "quando" tudo aconteceu. Como observa Frosh (2006, p. 266): "Eles (os jornalistas) estão lá, [com] sua sensação corporal e experiência de autoria, e testemunhando o conhecimento que transmitem a outros distantes". Mas a narrativa testemunhal construída pelos jornalistas brasileiros nos memoriais virtuais às vítimas da Covid-19 tem outra dinâmica. Eles efetivamente incorporam o papel de mediadores das dores e sensibilidades das vidas de estranhos, como se fossem suas também, de modo a atribuir força narrativa.

Assim, os testemunhos e as narrativas sensíveis tornados públicos nos memoriais on-line em homenagem às vítimas da Covid-19 tornam-se um novo acontecimento. Inúmeras pessoas saíram do anonimato para as telas da TV em rede nacional ao terem suas mortes mediadas nesses memoriais. Nestes, a morte como acontecimento perde força diante da enunciação do que o morto foi e fez em vida. Anônimos são repentinamente alçados à categoria de falecidos notabilizados, não por velórios e funerais majestosos com os das celebridades artísticas e políticas, mas, qual tal estes, pelas "narrativas que reconstroem trajetórias de vida, que, com a morte, são ressignificadas, dramatizadas e espetacularizadas" (RONDELLI; HERSCHMANN, 2000, p. 201), agora para consumo virtual e transmidiático.

\section{Análise pragmática da narrativa}

Este tópico sintetiza os dados de um estudo exploratório dos conteúdos publicados no Memorial Covid-19 do Portal G1, no período de 4 de junho a 20 de agosto de 2020, quando ocorreram os maiores picos de mortes na "primeira onda" da pandemia no país (respectivamente 1.473 e 1.204 em cada um desses dias $)^{10}$. Nesse intervalo foram publicados 158 mini textos em homenagem a essas vítimas na página web do Memorial (que variaram de 41 a 1.124 toques), dos quais 154 remetiam, por meio de links, a reportagens produzidas pelas equipes locais-regionais do Portal.

Cabe esclarecer, porém, que não foi possível identificar relações estatísticas entre as afiliadas que mais contribuíram para o Memorial com a cobertura local de óbitos provocados pela Covid-19 e os índices de casos fatais da doença, contabilizados pelo próprio G1 e posteriormente pelo consórcio de veículos de imprensa. O G1 do Acre, por exemplo, estado que sempre apareceu no mapa da pandemia com poucos casos, se comparado ao restante do país, foi o que publicou o maior número de matérias no Memorial do Portal no período analisado (28), seguido pelo G1 de Goiás (26). Esses números contrastam com as três publicações do G1 Amazonas, no período em que Manaus era um dos epicentros nacionais na primeira onda da pandemia no país.

Prosseguindo o levantamento das emissoras afiliadas à Rede Globo que contribuíram para o Memorial do G1, observou-se que mais de $80 \%$ das matérias têm origem em cidades do interior. No caso do estado de São Paulo, epicentro nacional da pandemia no Brasil, por exemplo, todos os 26 textos publicados vieram de emissoras de fora da capital, duas delas integrantes das redes regionais EPTV e TV TEM. O estado do Rio de Janeiro, segundo epicentro do país, contribuiu com apenas oito histórias, todas produzidas por cinco emissoras do interior fluminense.

Do ponto de vista metodológico, o breve estudo aqui apresentado inspira-se nos passos da análise pragmática da narrativa jornalística proposta por Luiz Gonzaga Motta (2008, p. 145), relativa a "um conjunto de notícias isoladas sobre um mesmo tema publicadas dia após dia, que aparentemente não possuem narratividade". Trata-

${ }^{10}$ Dados disponíveis no painel Covid-19 da Johns Hopkins University: https://github.com/CSSEGI-

SandData/COVID-19. -se de um procedimento que busca agrupar relatos noticiosos fragmentados em uma sequência ampliada, "como se fossem um acontecimento único e singular".

Os textos fragmentados aqui em questão são aqueles produzidos por equipes jornalísticas do G1 na cobertura cotidiana das ocorrências da pandemia no recorte 
regional sob a sua responsabilidade, daí o seu caráter multiterritorial. O "acontecimento único e singular" que se busca (re)construir é o das mortes por Covid-19 espalhadas pelo país, que despertam um sentido compartilhado de comoção pelo sofrimento alheio, associada ao medo do desconhecido e de um futuro incerto, ameaçado de ser abreviado a qualquer momento. Tal unicidade realiza-se por meio da interface agregadora do Memorial Covid-19 do Portal G1, ao qual as notícias locais sobre essas mortes são vinculadas por meio de links.

A existência dessa interface agregadora dispensa a necessidade do primeiro movimento da análise proposta por Motta (2008, p. 147-149), que é a de recomposição do acontecimento jornalístico, ainda em processo até a conclusão do estudo. $\mathrm{O}$ segundo movimento, de identificação dos conflitos, corresponde à dramaticidade que começa antes da consumação dos óbitos, com a busca por atendimento, diagnóstico correto por meio de testagem, internação, leitos de UTI com respirador, e se desdobra nas condições do enterro sem velório nem presença da família. Esses passos dramáticos são geralmente relembrados pelos familiares e amigos que relatam o acontecimento. Eventualmente, também aparecem conflitos relacionados ao cumprimento ou não do distanciamento social, por vontade própria ou por negligência em relação a trabalhadores dos grupos de risco.

O terceiro movimento, de construção de personagens jornalísticas, relaciona-se à identificação dos traços positivos das vítimas, geralmente expressos por pessoas próximas, por elos familiares, de amizade, de trabalho ou até circunstanciais. No caso das mortes por Covid-19, este movimento vincula-se também ao que Motta (2008, p. 147-149) identifica como metanarrativas, que correspondem a "significados de fundo moral ou fábula da história", operadas narrativamente por meio da heroicização dos personagens sacrificados pelo vírus.

No quarto movimento, o das estratégias comunicativas, a análise se deterá em um aspecto específico, não incluído nos procedimentos de Motta (2008), que é o do princípio da proximidade com os acontecimentos e personagens da notícia, fundamental para a abordagem do "foco narrativo", que para Motta (2008) está incluído no quinto movimento da análise. Estende-se, aqui, a compreensão de Chouliaraki (2008), de que a mídia hierarquiza os conteúdos da narrativa em escalas de proximidade (física ou simbólica) entre as audiências e os sofredores.

Assim, associando os passos metodológicos propostos por Motta (2008) às reflexões anteriormente apresentadas sobre a mediação do sofrimento alheio pela mídia, foram identificadas quatro grandes linhas de construções narrativas nas quais o jornalista incorpora em seu discurso pretensamente objetivo os testemunhos afetivos e sensíveis à dor alheia. Dos 154 textos contabilizados: 36 (23\%) dão ênfase ao dramático esforço de pessoas para manter a vida e a saúde enquanto buscam atendimento médico adequado para os sintomas da Covid-19; outros $23 \%$ (35) narram experiências igualmente dramáticas de luto em família, com perdas simultâneas de parentes próximos; 29 (19\%) privilegiam a lembrança de parentes, amigos e colegas de trabalho sobre as qualidades das vítimas em vida, como se fossem "compensações" pela morte; 40 (26\%) seguem o princípio de proximidade como estratégica comunicativa, centrando suas narrativas em vítimas notabilizadas localmente, de prefeitos a empresários, de médicos a professores; de estilista a policiais; e 14 (9\%) não puderam ser enquadrados em nenhuma dessas linhas, por insuficiência de informações.

Trabalhadores da saúde (sobretudo médicos, técnicos de enfermagem e enfermeiros - homens e mulheres) lideram a qualificação profissional das vítimas, em 33\% das histórias contadas, seguidos pelos profissionais de segurança e forças militares (15\%), políticos (6\%) e aposentados (5\%), por conta do peso dos idosos entre os falecimentos pela Covid-19. Os retratados restantes estão pulverizados em 27 outras atividades laborais, exceto aqueles em que essa categorização não se aplica: indígenas, crianças, dona de casa, estudante, preso, religiosa, voluntário. Em 
termos de faixa etária, as vítimas reportadas pelo Memorial do G1 no período estudado distribuem-se da seguinte forma: 55 idosos de 60 a 92 anos; 87 adultos de 23 a 59 anos; cinco crianças de 11 meses a 12 anos; e sete com idades não informadas.

Os subtópicos a seguir apresentam um panorama dessas categorizações e exemplos ilustrativos das suas principais características, algumas das quais poderiam receber mais de um enquadramento. Por se tratar de uma abordagem sensível, os nomes dos personagens citados nos trechos selecionados foram propositalmente excluídos, à exceção de o de uma pessoa com visibilidade pública nacional.

\section{a) O drama para manter a vida}

Nessa categoria foram identificadas narrativas que dão ênfase ao esforço de pessoas comuns que nos momentos mais graves da "primeira onda" da pandemia no Brasil peregrinaram pelas cidades em busca de internação, de respiradores, de UTI, que tiveram diagnóstico errado ou estado de saúde negligenciado, ou então, ao contrário, resistiram a buscar atendimento e faleceram em casa, ou foram hospitalizadas tarde demais. Como um lavrador de 78 anos que faleceu após três dias esperando por uma vaga de UTI. "Segundo a Secretaria de Saúde de Goiás, ele não teve condições clínicas de ser levado à primeira vaga que saiu para ele e morreu antes de ser transportado para a segunda" (G1 GO/ TV Anhanguera, 20/06/20). Ou o professor de português, de 27 anos, que por ser asmático resistiu a procurar atendimento médico, por medo de ser contaminado, e optou por permanecer em casa, na cidade de Caridade (CE).

O quadro acabou se agravando por três dias e, então, ele decidiu ir ao hospital. Em seguida, foi transferido para Tauá e, depois, para a UTI de Crateús, pois necessitava de hemodiálise. Para a prima [...], os parentes e amigos tinham esperança de que ele iria se recuperar. Contudo, apesar do quadro clínico, que aparentava ser estável, a evolução da doença foi uma surpresa muito triste (G1 CE/ TV Verdes Mares, 11/06/2020).

Enquanto o professor tentava se curar, a esposa de 25 anos deu à luz os filhos Téo e Bento, que ele não chegou a conhecer. A descrença no poder do vírus também vitimou um jovem soldado da Polícia Militar da cidade de Registro (SP), conforme relato de um amigo, que o encontrou no quartel já bastante debilitado, mas ouviu dele que seria "apenas um resfriado". Ao passar pela triagem, o PM foi transferido imediatamente para um hospital. "No primeiro dia, ele ainda mandou mensagem no grupo do pelotão, mas dias depois já foi induzido ao coma”, lamenta o amigo (G1 Santos/ TV Tribuna, 11/06/2020).

Descasos de empregadores quanto à gravidade da pandemia também causaram mortes e questionamentos de entidades de classe, como o do Sindicato dos Servidores Públicos Municipais de Belo Horizonte (Sindibel) em relação a um técnico de enfermagem de 54 anos (G1 MG/ Globo Minas, 08/08/2020). Ele era diabético e trabalhava em uma Unidade de Pronto Atendimento (UPA) de Belo Horizonte, mas não foi afastado do trabalho durante a fase mais aguda do distanciamento social recomendado pela OMS - Organização Mundial da Saúde e faleceu de Covid-19.

\section{b) O luto em família}

Casos de orfandade precoce, de famílias desmontadas, de projetos de maternidade desfeitos são conseqüências da contaminação doméstica ou comunitária que resulta em dor coletiva entre parentes próximos. Como a história de uma grávida de 38 anos diagnosticada com a Covid-19 em Mato Grosso, que foi transferida para um hospital particular em Goiás quando seu estado de saúde se agravou. Ela deu à luz uma menina com 34 semanas de gestação, mas morreu um mês depois 
sem ter tido contato com a bebê (G1 GO/ TV Anhanguera, 25/07/2020). Também vítima desta doença, a gestora da Reserva Extrativista do Cazumbá-Iracema, em Sena Madureira (AC), de 35 anos, que morava com a mãe idosa, deixou um filho de apenas 15 dias de vida (G1 AC/ Rede Amazônica, 25/07/2020).

A morte de um clínico geral da UPA do Campo Grande, em Campinas, pai de três médicas, e que já havia sido diretor do time de futebol Ponte Preta, entre 2011 e 2014, gerou comoção entre familiares, amigos e pacientes. Horas após se despedir do médico, a mulher dele fez um apelo contundente sobre a necessidade de ações preventivas contra a Covid-19 (G1/ EPTV Campinas e Região, 09/06/2020).

Vivendo o luto de perder dois parentes em um curto intervalo de tempo, uma família de Belo Horizonte ainda teve que lidar com um outro problema - o preconceito, que levou o filho de uma das vítimas, de 40 anos, a fazer um desabafo: "O pessoal tem inventado muita história, falando que a gente tem o vírus. Já olha pra gente de um jeito torto. Não bastasse a dor de perder gente da gente, ainda temos que lidar com essas situações de desrespeito de outras pessoas" (G1 MG, Globo Minas, 19/06/2020). Mesmo quando alguém se recupera da Covid-19, pode ter que enfrentar a dor do luto, como um idoso que teve alta do hospital uma semana após morte da esposa, que faleceu no dia do aniversário de 41 anos de casamento deles (G1 PB, 25/07/2020).

\section{c) Qualidades da vida, após a morte}

A transversalidade territorial dos afetados tragicamente pela pandemia aparece no enaltecimento das qualidades dos mortos, que os equalizam, independentemente da profissão, da idade, dos postos de poder que exerceram e dos espaços vividos. Nessas narrativas aparecem com frequência expressões como "uma pessoa de luz", "lutar pelo próximo" e "lutou um bom combate".

O pai do secretário de Saúde do Tocantins, por exemplo, será lembrado pela família como alguém alegre, brincalhão. O professor, biólogo e arqueólogo de Goiás como "uma pessoa iluminada, que ajudou muita gente e muito dedicado à profissão", segundo a esposa. O empresário e ex-árbitro por ter dedicado muitos anos de sua vida ao futebol paraibano, incluindo o comando da extinta Coordenadoria dos Estádios da Paraíba (Codepar) e a presidência do Esporte Clube Cabo Branco, além da banda de axé Bereguedê, de João Pessoa, da qual foi empresário (G1 PB, 08/06/2020).

É notória, no Memorial do G1, a exaltação de profissionais de saúde como aqueles que mais se sacrificaram "pela vida de todos". O cirurgião diabético da cidade de Santa Isabel (interior de São Paulo) sabia o risco que corria ao atender pacientes de Covid-19 em uma UTI. A esposa dele chegou a pedir que deixasse o trabalho, mas ele respondeu em uma mensagem de texto: "Meu lugar é aqui, na frente de batalha". Ele morreu no Hospital das Clínicas de São Paulo, depois de 20 dias entubado (G1 Mogi das Cruzes e Suzano/ TV Diário, 25/07/2020).

A médica patologista de 67 anos, que foi professora da Unicamp por três décadas, tinha câncer controlado há 15 anos e ainda sofria de diabetes e problemas cardíacos, segundo a família. Mas atuava em dois laboratórios de Campinas (SP) quando foi contaminada e faleceu após duas semanas internada no Hospital PUC Campinas. "Ensinou muita gente. Tinha um coração enorme", disse um sobrinho. O primeiro médico no exercício da atividade a perder a vida por causa do novo coronavírus no Paraná tinha 33 anos, fazia residência em ortopedia e era plantonista em uma unidade estadual de saúde em Bocaiúva do Sul, na região metropolitana de Curitiba. "A dor é irreparável. Ele se foi lutando pela vida do próximo. Ele era visto como um herói na família", comentou o irmão (G1 PR/ RPC TV, 22/06/2020).

Mas poucas histórias ilustram tão fortemente a heroicização dos profissionais de saúde pela mídia brasileira como a da técnica de enfermagem de 45 anos que teve a foto dela vestida de Mulher Maravilha divulgada no Memorial. Sua "lápide 
virtual" diz que ela "ficou feliz ao conquistar uma vaga para trabalhar no Hospital de Campanha de Suzano" e que desde que a pandemia começou, "queria ajudar de alguma forma", segundo depoimento de uma filha. Outra filha contou que "guarda orgulhosa a lembrança de alguém que lutou para salvar a vida de outras pessoas" (G1 Mogi-Suzano, 26/06/2020).

d) O princípio de proximidade

O princípio de proximidade com os lugares de referência das narrativas é uma estratégia comunicativa clara das afiliadas da Globo que contribuíram para o Memorial do G1 no período estudado. Ele é demarcado de muitas formas nos textos publicados, podendo referir-se ao local de nascimento ou de ocorrência da morte, de moradia ou de construção da carreira, ou mesmo a personagens do cotidiano, como o vendedor de doces na rodoviária de Rio Bonito, no Leste fluminense. Mas os traços mais marcantes dessa proximidade são a relação com o poder local (evidenciado no tratamento a políticos falecidos pela Covid-19), o uso de apelidos e as referências espaciais que dependem de vivência para serem reconhecidas. Também são significativas as notas de pesar, a decretação de luto oficial e a realização de cortejos em homenagem a pessoas notórias nas cidades, de comerciantes a professores, de médicos a policiais militares.

O prefeito de Botelhos, no Sul de Minas Gerais, enviou solidariedade à família da professora e diretora de uma escola municipal que foi a primeira a falecer de Covid-19 na cidade e decretou luto oficial de três dias (EPTV Sul de Minas, 06/06/2020). Em São Francisco de Itabapoana (RJ), colegas de trabalho de um guarda municipal de 45 anos, que "era muito querido", despediram-se dele "em um cortejo emocionante" (G1/ InterTV Norte Fluminense, 06/08/2020).

Já o cortejo em homenagem ao prefeito Borebi, na região de Bauru (SP), que iria percorrer as principais ruas da cidade, foi proibido pela Defesa Civil. Por isso, veículos ficaram estacionados e moradores soltaram balões brancos enquanto o carro da funerária passava pelo portão de entrada da cidade. Segundo o secretário de saúde e amigo do prefeito: "A cidade sente muito, a região sente muito" (G1/ TV TEM Bauru e Marília, 20/06/2020).

Ressalte-se que mesmo quando o protagonista da notícia é alguém com notoriedade nacional, os referenciais de proximidade predominam na narrativa. É o caso do médico e pesquisador baiano Elsimar Coutinho, notabilizado internacionalmente por seus estudos na área de reprodução humana, que morreu aos 90 anos, após complicações da Covid-19. Na matéria do G1 Bahia, o governador Rui Costa destaca que o cientista levou "o nome da Bahia para todo o mundo", enquanto o então prefeito de Salvador, ACM Neto, afirma que "a Bahia e o Brasil perdem um patrimônio, uma inteligência rara”. Em nota de pesar, a Universidade Federal da Bahia (UFBA) destacou que "foi como professor e pesquisador da Faculdade de Medicina da Bahia (FMB) que Elsimar Coutinho iniciou os seus estudos sobre a progesterona e sua ação na prevenção do trabalho de parto prematuro e descreveu o efeito anticoncepcional da substância" (G1 BA/ TV Bahia, 17/08/2020).

\section{Considerações finais}

Um acontecimento de escala planetária como a pandemia provocada pelo novo coronavírus representa um desafio para o jornalismo, no confronto entre a universalidade e as particularidades das suas manifestações nos diferentes recortes geográficos das notícias. Nos primeiros dois meses de circulação do vírus no Brasil, a divulgação diária de novos casos suspeitos, confirmados e fatais da Covid-19, aliada à falta de informação sobre os modos de contaminação, deixava as pessoas perplexas, especialmente jornalistas, atônitos com a velocidade das "novidades", e 
pesquisadores da área de saúde, fontes privilegiadas instadas a dar respostas rápidas a um fenômeno desconhecido e traiçoeiro (AGUIAR, 2020).

Mas naquele mar de números e dramas, nomes, rostos e histórias de vida começaram a emergir das coberturas locais, da proximidade com os acontecimentos, a partir do olhar endógeno sobre fatos e personagens da pandemia. Foram os relatos dessas histórias vivenciadas e testemunhadas que viabilizaram os memoriais das vítimas da Covid-19 como agregadores de narrativas das experiências de vida e de morte.

Este artigo buscou articular uma literatura que aborda o tratamento dado pela mídia, e pelo jornalismo em particular, a acontecimentos que envolvem o sofrimento de pessoas distantes da audiência em foco com um contexto empírico regido pelo princípio de proximidade. Nesta perspectiva, as condições de produção desses relatos são observadas a partir de uma ruptura da lógica jornalística que prega o distanciamento e a objetividade em relação a fatos e fontes, em favor de um "jornalismo sensível”, regido pela empatia acerca da dor alheia.

Evidencia-se, assim, que o Memorial Covid-19 do Portal G1 (assim como o website colaborativo Inumeráveis) é fruto de uma "guinada moral" em relação à cobertura jornalística da pandemia, que durante pelo menos dois meses supervalorizou os números de doentes e mortos - tratando-os como eventos distantes -, sem considerar as experiências de vida por trás desses acontecimentos.

Assim, além dos relatos baseados em índices racionais da pandemia, a cobertura jornalística da Covid-19 no Brasil ganha narrativas sensíveis ao sofrimento dos por ela afetados, orientadas por testemunhos midiáticos e pelo princípio de proximidade. No caso do Portal G1, merece destaque o fato de essas narrativas serem pautadas por uma perspectiva de proximidade típicas das relações de cidades do interior, origem de mais de $80 \%$ das matérias sobre mortes por Covid-19 veiculadas no período estudado.

\section{Referências}

AGUIAR, Sonia. COVID-19: a doença dos espaços de fluxos. GEOgraphia, v. 22, n. 48, 2020. Disponível em: https://periodicos.uff.br/geographia/article/ view/42848/24513. Acesso em: 10 ago. 2020.

BASÍLIO, Ana Luiza. Inumeráveis: Projeto cria memorial em homenagem às vítimas do coronavírus. Carta Capital (on-line), 21 de maio de 2020. Disponível em: https://www.cartacapital.com.br/sociedade/inumeraveis-projeto-cria-memorial-em-homenagem-as-vitimas-do-coronavirus/. Acesso em: 20 ago. 2020.

CHOULIARAKI, Lilie. The mediation of suffering and the vision of a cosmopolitan public. Television \& new media, v. 9, n. 5. p. 371-391, 2008. Disponível em: https://journals-sagepub-com.ez20.periodicos.capes.gov.br/doi/ pdf/10.1177/1527476408315496. Acesso em: 30 ago. 2020.

EL PAÍS TV. El País entrevista nesta quarta o artista Edson Pavoni, criador do projeto Inumeráveis. El País Brasil, 18 de agosto de 2020. Disponível em: https:// brasil.elpais.com/brasil/2020-08-18/el-pais-entrevista-nesta-quarta-o-artista-edson-pavoni-criador-do-projeto-inumeraveis.html. Acesso em: 20 ago. 2020.

EPTV Sul de Minas, 06/06/2020. Botelhos confirma $1^{a}$ morte por coronavírus; cidades têm 20 novos casos. Por EPTV 2 [Sul de Minas] - Botelhos, MG, 06/06/2020. Disponível em: https://g1.globo.com/mg/sul-de-minas/noticia/2020/06/06/casos-de-coronavirus-no-sul-de-minas-de-sabado-6-de-junho.ghtml. Acesso em: 20 ago. 2020. 
FROSH, Paul; PINCHEVSKI, Amit. Media witnessing and the ripeness of time. Cultural Studies, v. 28, n. 4, p. 594-610, 2014. Disponível em: https://www.tandfonline.com/doi/abs/10.1080/09502386.2014.891304. Acesso em: 20 ago. 2020.

FROSH, Paul. Telling Presences: Witnessing, mass media, and the imagined lives of strangers. Critical Studies in Media Communication, v. 23, n. 4, p. 265-284, 2006. Disponível em:https://www.tandfonline.com/doi/abs/10.1080/07393180600933097. Acesso em: 20 ago. 2020.

G1 AC/ Rede Amazônica, 25/07/2020. Gestora de reserva extrativista no interior do Acre morre vítima de Covid-19. Por Iryá Rodrigues, G1 AC - Rio Branco, 27 de jul. 2020. Disponível em: https://g1.globo.com/ac/acre/noticia/2020/07/27/gestora-de-reserva-extrativista-no-interior-do-acre-morre-vitima-de-covid-19.ghtml? $\mathrm{ga}=2.56428203 .1424480647 .1610588913-\mathrm{d} 9 \mathrm{~b} 75 \mathrm{a} 43-48 \mathrm{a} 2-353 \mathrm{a}-\mathrm{c} 8 \mathrm{bc}-\mathrm{d} 0 \mathrm{~d} 5 \mathrm{~b} 0 \mathrm{a} 01487$. Acesso em: 20 ago. 2020.

G1 BA/ TV Bahia, 17/08/2020. Elsimar Coutinho, médico cientista, morre aos 90 anos após complicações da Covid-19. Por G1 BA, 17/08/2020. Disponível em: https://g1.globo.com/ba/bahia/noticia/2020/08/17/morre-aos-90-anos-elsimar-coutinho.ghtml?_ga=2.145375604.1525189142.1610416366-d9b75a43-48a2-353a-c8bc-d0d5b0a01487. Acesso em: 20 ago. 2020.

G1 CE/ TV Verdes Mares, 11/06/2020. Professor morre por Covid-19 um dia antes do nascimento dos filhos gêmeos no Ceará. Por Honório Barbosa, G1 CE, 11 de jun. 2020. Disponível em: https:/g1.globo.com/ce/ceara/noticia/2020/06/11/professor-morre-por-covid-19-um-dia-antes-do-nascimento-dos-filhos-gemeos-no-ceara.ghtml. Acesso em: 20 ago. 2020.

G1 GO/ TV Anhanguera, 20/06/20. Idoso morre com Covid-19 após três dias à espera por UTI em Goiás; onze parentes têm coronavírus. Por Vanessa Martins, G1 GO, 20 jun. de 2020. Disponível em: https:/g1.globo.com/go/goias/noticia/2020/06/20/idoso-que-testou-positivo-para-covid-19-morre-enquanto-esperava-ser-transferido-para-uti-em-goias.ghtml. Acesso em: 20 ago. 2020.

G1 GO/ TV Anhanguera, 25/07/2020. Mãe morre de Covid-19 em Goiânia antes de conhecer a filha bebê. Vitor Santana, G1 GO, 26 de jul. 2020. Disponível em: https:/g1.globo.com/go/goias/noticia/2020/07/26/mulher-morre-de-covid-19-em-goiania-antes-de-conhecer-a-filha.ghtml?_ga=2.98511775.1424480647. 1610588913-d9b75a43-48a2-353a-c8bc-d0d5b0a01487. Acesso em: 20 ago. 2020.

G1 MG, Globo Minas, 19/06/2020. Pai e filha morrem com Covid-19 em Belo Horizonte. Por Carlos Eduardo Alvim, TV Globo - Belo Horizonte. 19 jun. 2020. Disponível em: https:/g1.globo.com/mg/minas-gerais/noticia/2020/06/19/pai-e-filha-morrem-com-covid-19-em-belo-horizonte.ghtml. Acesso em: 20 ago. 2020.

G1 MG/ Globo Minas, 08/08/2020. Técnico de enfermagem do Odilon Behrens é o segundo profissional de saúde de $\mathrm{BH}$ a morrer de Covid-19, diz sindicato. Por Cíntia Neves, G1 Minas - Belo Horizonte, 08 de ago. 2020. Disponível em: https://g1.globo.com/mg/minas-gerais/noticia/2020/08/08/tecnico-de-enfermagem-do-odilon-behrens-e-o-segundo-profissional-de-saude-de-bh-a-morrer-de-covid-19-diz-sindicato.ghtml?_ga=2.92490397.1601401911.16216280991860726150.1621628095. Acesso em: 20 ago. 2020.

G1 MINAS GERAIS. Pessoas por trás dos números: perdeu alguém para a Co- 
vid-19? Compartilhe a história de vida que ela guardava. Belo Horizonte: G1 Minas, 25 de jun. de 2020. Disponível em: https:/g1.globo.com/mg/minas-gerais/ Acesso em: 20 de jul. 2020.

G1 Mogi das Cruzes e Suzano/ TV Diário, 25/07/2020. Médico morre dois meses após mulher pedir para deixar trabalho em UTI para Covid-19: 'Meu lugar é aqui, na frente de batalha'. Por Gladys Peixoto, G1 Mogi da Cruzes e Suzano/ TV Diário, 25 de jul. 2020. Disponível em: https://g1.globo.com/sp/mogi-das-cruzes-suzano/. Acesso em: 20 ago. 2020.

G1 Mogi-Suzano, 26/06/2020. Técnica de enfermagem que morreu com Covid-19 celebrou vaga em hospital de campanha; 'Foi uma heroína', diz filha. G1 Mogi das Cruzes e Suzano, 26 de jun. 2020. Disponível em: https://g1.globo.com/sp/ mogi-das-cruzes-suzano/noticia/2020/06/26/tecnica-de-enfermagem-que-morreu-com-covid-19-celebrou-vaga-em-hospital-de-campanha-foi-uma-heroina-diz-filha.ghtml. Acesso em: 20 ago. 2020.

G1 PB, 08/06/2020. Empresário e ex-presidente da Comissão de Arbitragem da PB morre de Covid-19, em João Pessoa. Por G1 PB, 08/06/2020. Disponível: https:// g1.globo.com/pb/paraiba/noticia/2020/06/08/empresario-e-ex-presidente-da-comissao-de-arbitragem-da-pb-morre-de-covid-19-em-joao-pessoa.ghtml. Acesso em: 20 ago. 2020

G1 PB, 25/07/2020. Idoso se recupera da Covid-19 uma semana após morte da esposa na PB: 'estava sempre rindo', diz filha. Por Iara Alves, G1 PB, 25 de jul. 2020. Disponível em: https://g1.globo.com/pb/paraiba/noticia/2020/07/25/idoso-se-recupera-da-covid-19-uma-semana-apos-morte-da-esposa-na-pb-estava-sempre-rindo-diz-filha.ghtml. Acesso em: 20 ago. 2020.

G1 PR/ RPC TV, 22/06/2020. 'Era visto como um herói', diz irmão de médico residente que morreu por causa da Covid-19 em Curitiba. Por RPC Curitiba, 24/06/2020. Disponível em: https://g1.globo.com/pr/parana/noticia/2020/06/24/ era-visto-como-um-heroi-diz-irmao-de-medico-residente-que-morreu-por-causa-da-covid-19-em-curitiba.ghtml. Acesso em: 20 ago. 2020.

G1 Santos/ TV Tribuna, 11/06/2020. Jovem morre de coronavírus dias após se formar como soldado da PM. Por Isabella Lima, G1 Santos, 11 de jun. 2020. Disponível em: https:/g1.globo.com/sp/santos-regiao/noticia/2020/06/11/jovem-morre-de-coronavirus-dias-apos-se-formar-como-soldado-da-pm.ghtml. Acesso em: 20 ago. 2020.

G1, Especiais Globo. Programa Bem Estar. Memorial das Vítimas da Covid. Disponível em: http://especiais.g1.globo.com/bemestar/coronavirus/memorial-vitimas-covid-19/?\&_ga=2.208764370.1959889609.1594673458-349861249.1594673458\#/. Acesso: 20 de jul. 2020.

G1/ EPTV Campinas e Região, 09/06/2020. Médico vítima da Covid-19 em Campinas fazia plantão com a filha em UPA e foi diretor na Ponte Preta. Por G1 Campinas e Região, 09/06/2020. Disponível em: https:/g1.globo.com/sp/campinas-regiao/ noticia/2020/06/10/covid-19-morte-de-medico-que-atuava-em-upa-de-campinas-e-foi-diretor-na-ponte-gera-comocao-alegria-em-ajudar-as-pessoas.ghtml? $\mathrm{ga}=2.37077920 .1424480647 .1610588913-\mathrm{d} 9 \mathrm{~b} 75 \mathrm{a} 43-48 \mathrm{a} 2-353 \mathrm{a}-\mathrm{c} 8 \mathrm{bc}-\mathrm{d} 0 \mathrm{~d} 5 \mathrm{~b} 0 \mathrm{a} 01487$. Acesso em: 20 ago. 2020. 
G1/ InterTV Norte Fluminense, 06/08/2020. Guarda municipal morre vítima da Covid-19 em SãoFrancisco de Itabapoana, no RJ.Por G1 NorteFluminense, 07/08/2020. Disponível em: https:/g1.globo.com/rj/norte-fluminense/noticia/2020/08/07/guarda-municipal-morre-vitima-da-covid-19-em-sao-francisco-de-itabapoana-no-rj. ghtml?_ga=2.250793926.1525189142.1610416366-d9b75a43-48a2-353a-c8bc-d0d5b0a01487. Acesso em: 20 ago. 2020.

G1/ TV TEM Bauru e Marília, 20/06/2020. Morre prefeito de Borebi que contraiu Covid-19. Por G1 Bauru e Marília, 20/06/2020. Disponível em: https:/g1.globo. com/sp/bauru-marilia/noticia/2020/06/20/morre-prefeito-de-borebi-que-contraiu-covid-19.ghtml?_ga=2.99094046.1424480647.1610588913-d9b75a43-48a2-353a-c8bc-d0d5b0a01487. Acesso em: 20 ago. 2020.

HELAL, Ronaldo; CATALDO, Graziella. A morte e o mito: as narrativas da imprensa na cobertura jornalística da morte de Ayrton Senna. In: XXVII CONGRESSO BRASILEIRO DE CIÊNCIAS DA COMUNICAÇÃO. Anais..., Porto Alegre: Intercom, 2004. Disponível em: http://cev.org.br/arquivo/biblioteca/4036683.pdf. Acesso: 13 de jul. 2020.

KYRIAKIDOU, Maria. Media witnessing: exploring the audience of distant suffering. Media, Culture \& Society, v. 37, n. 2, p. 215-231, 2015. Disponível em: https:// journals.sagepub.com/doi/10.1177/0163443714557981. Acesso: 20 de jul. 2020.

MOTTA, Luiz. Análise pragmática da narrativa jornalística. In: LAGO, C.; BENETTI, M. (Orgs.). Metodologia de pesquisa em jornalismo. 2. ed. Petrópolis (RJ): Vozes, 2008, p. 143-167.

ONG, Jonathan Corpus. "Witnessing" or "mediating" distant suffering? Ethical questions across moments of text, production, and reception. Television \& New Media, v. 15, n. 3, p. 179-196, 2014. Disponível em: https://journals.sagepub.com/ doi/10.1177/1527476412454687. Acesso em: 14 de jul. 2020.

RONDELLI, Elizabeth; HERSCHMANN, Micael. A mídia e a construção do biográfico: o sensacionalismo da morte em cena. Tempo Social, v. 12, n. 1, 2000. Disponível em: https://www.scielo.br/pdf/ts/v12n1/v12nla11.pdf. Acesso em: 13 de jul. 2020.

VALLE, Eduardo. Conheça a história do memorial online que relembra vítimas da pandemia. GQ Globo.com, 06 de mai. de 2020. Disponível em: https:/gq.globo. com/Noticias/noticia/2020/05/conheca-historia-do-memorial-online-que-relembra-vitimas-da-pandemia.html. Acesso em: 20 ago. 2020.

VILLA, Mirian. Memorial Inumeráveis: site conta história de vítimas do coronavírus no Brasil. Paraná Portal, 07 de mai. de 2020 (on-line). Disponível em: https:// paranaportal.uol.com.br/geral/memorial-inumeraveis-historia-vitimas-coronavirus/. Acesso em: 14 de jul. 2020. 